\title{
Penerapan Hukum Mortalita Gompertz untuk Perhitungan Dana Tabarru' dengan Metode Cost of Insurance
}

\author{
Fauziah Noor Hidayat ${ }^{1, a)}$, Rini Cahyandari ${ }^{1, b)}$, Asep Solih Awalluddin ${ }^{1, c)}$ \\ ${ }^{1}$ Jurusan Matematika, Fakultas Sains dan Teknologi, UIN Sunan Gunung Djati bandung \\ a)email: fauziah2218@gmail.com \\ b)email: rcahyandari@yahoo.com \\ c)email: aasolih@gmail.com
}

\begin{abstract}
Abstrak
Berdasarkan cara pengelolaan dananya, asuransi syari'ah dibedakan menjadi dua, asuransi dengan unsur tabungan dan asuransi tanpa unsur tabungan. Didalam asuransi tanpa unsur tabungan, dana yang diberikan oleh peserta asuransi akan dimasukkan ke dalam satu rekening saja, yaitu rekening tabarru'. Sehingga adanya ketidakjelasan dalam presentase dana tabarru'. Cost of Insurance merupakan metode yang digunakan dalam perhitungan dana tabarru' yang terdiri dari beberapa komponen yaitu: tabel mortalita yang digunakan, asumsi hasil investasi (i) dan asumsi biaya pengelolaan $(\alpha)$. Didalam penelitian ini dilakukan perhitungan tabel mortalita dengan Hukum Gompertz yang memperhitungan risiko karena faktor usia, didalam perhitungannya dibutuhkan data acak usia yang berdistribusi Gompertz. Tabel mortalita dengan Hukum Gompertz ini yang akan digunakan untuk perhitungan dana tabarru'. Penulis menggunakan ilustrasi dengan usia peserta 41 tahun, tingkat investasi sebesar $5 \%$, dan biaya pengelolaan sebesar 30\%. Didapatkan dana tabarru' dengan menggunakan metode Cost of Insurance sebesar Rp. 156.762/bulan.
\end{abstract}

Kata kunci: Hukum Mortalita Gompertz, Dana Tabarru', dan Metode Cost of Insurance

Abstract
Based on the technique of fund management, Islamic insurance is divided into two; insurance with savings and insurance without savings. In linstrance witholit savings, the funds provided by insurance participants will be included in one account only, namely the tabarru account, So there is obscurity in the percentage of tabarru funds'. Cost of Insurance is a method to count tabarru' funds which consists of several components; mortality table, investment returns assumption(i) dan management cost assumption ( $\alpha$ ). This research is calculating mortality table by using Gompertz Law which calculates risk by the factor of the age it takes random age data that has Gompertz distribution. This mortality table that uses Gompertz law will be used to count tabbaru' funds. The writer uses illustration of company data with 41 years of age, $5 \%$ investment level, and 30\% cost management. The result of tabarru' fund using COI method is amounting to Rp.156.762/bulan.

Key words: Gompertz Mortality Law, Tabarru' fund and Cost of Insurance Method

\section{Pendahuluan}

Manusia tidak dapat memprediksi apa yang akan terjadi di masa yang akan datang, seperti kecelakaan, sakit, termasuk mati. Karena itu perlu adanya tindakan yang dapat menanggulangi risiko tersebut.

Asuransi merupakan lembaga keuangan non bank yang menawarkan berbagai macam produk. Pada umumnya asuransi adalah usaha untuk memindahkan risiko dari nasabah kepada perusahaan asuransi. 
Sedangkan asuransi syariah mengandung prinsip risk sharing, yaitu berbagi atau saling memikul risiko antar nasabah sehingga setiap nasabah menjadi penanggung dari musibah yang dihadapi oleh nasabah lainnya.

Asuransi syariah sudah berkembang di Indonesia yang ditandai dengan banyaknya perusahaan asuransi yang bermunculan. Bukan hanya itu, masyarakat Indonesia juga sudah banyak menggunakan produk asuransi syariah dengan beralasan asuransi syariah merupakan solusi untuk menanggulangi risiko mereka dimasa yang akan datang, karena sistem operasionalnya sesuai dengan aturan Islam.

Didalam asuransi terdapat beberapa jenis produk, misalnya asuransi jiwa, asuransi kecelakaan, asuransi kendaraan dan yang lainnya. Asuransi jiwa merupakan usaha untuk menanggung kerugian yang diakibatkan karena meninggalnya seseorang. Berdasarkan mekanisme pengelolaan dananya, asuransi jiwa syariah terbagi menjadi dua yaitu asuransi dengan unsur tabungan (saving) dan asuransi tanpa unsur tabungan (non saving). Asuransi dengan unsur tabungan, premi akan dibagi kedalam dua tabungan, yaitu rekening pribadi dan rekening tabarru', contoh produknya seperti asuransi dana investasi, asuransi pendidikan, dan asuransi dana haji. Adapun, asuransi tanpa unsur tabungan, premi yang dibayarkan oleh peserta asuransi hanya akan dimasukkan ke dalam satu rekening saja, yaitu rekening tabarru', produk asuransi non saving seperti asuransi kesehatan individu, dan asuransi kecelakaan diri individu.

Salah satu hal yang membedakan antara asuransi syariah dengan asuransi konvensional adalah adanya dana tabarru'. Dana tabarru' merupakan dana yang dikumpulkan dengan niat tolong menolong, peserta asuransi akan mendapatkan klaim dari dana tabarru' tersebut apabila terkena musibah. Di dalam asuransi jiwa syariah tanpa unsur tabungan tidak ada pembagian premi secara khusus kedalam rekening tabarru' yang menyebabkan adanya kebingungan pembagian dana tabarru' oleh karena itu penulis menggunakan metode Cost of Insurance dalam perhitungan dana tabarru'.

Berdasarkan penguraian tersebut penulis memberi judul untuk skripsi ini dengan "Penerapan Hukum Mortalita Gompertz untuk Perhitungan Dana Tabarru' dengan Metode Cost Of Insurance"

\section{Metode}

Terdapat beberapa hukum dalam perhitungan mortalita, diantaranya Gompertz, De Moivre, Makeham, dan Weilbull. Hukum yang digunakan pada pembahasan ini adalah hukum mortalita Gompertz. Distribusi Gompertz merupakan salah satu distribusi yang digunakan dalam menggambarkan usia kematian seseorang. Laju tingkat kematian untuk hykum Gompertzadalah:ka

$$
\mu_{x}=B c^{x}, \quad B>0, c>1, x \geq 0 \text {. }
$$

Parameter $B$ dikaitkan dengan tingkat kemungkinan meninggal, dan parameter $\mathrm{c}$ adalah peningkatan kegagalan atau kematian [13].

Fungsi peluang ${ }_{t} p_{x}$ dan ${ }_{t} q_{x}$ menurut fungsi distribusi Gompertz [14].

$$
\begin{aligned}
& { }_{t} p_{X}=\exp \left[-\frac{B c^{x}}{\ln c}\left(c^{t}-1\right)\right] \\
& { }_{t} q_{x}=1-\exp \left[-\frac{B c^{x}}{\ln c}\left(c^{t}-1\right)\right]
\end{aligned}
$$

Fungsi ketahanan hidup atau survival function untuk hukum Gompertz adalah

$$
s(x)=\exp \left[-\frac{B}{\ln c}\left(c^{x}-1\right)\right]
$$

Sehingga untuk melengkapi tabel mortalita dengan hukum Gompertz kita dapatkan persamaanpersamaan berikut

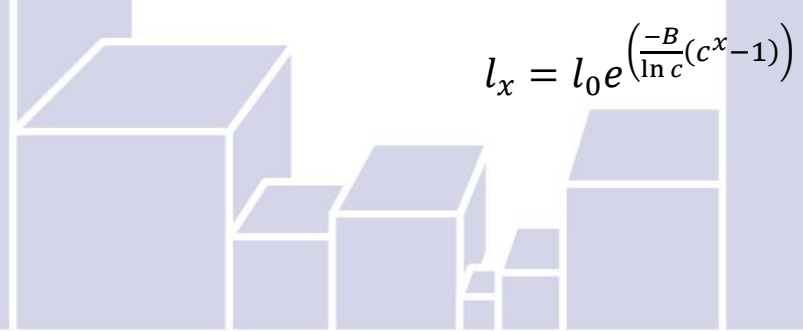




$$
\begin{aligned}
& d_{x}=l_{0} e^{\left(\frac{-B}{\ln c}\left(c^{x}-1\right)\right)}-l_{0} e^{\left(\frac{-B}{\ln c}\left(c^{x+1}-1\right)\right)} \\
& p_{x}=\exp \left[-\frac{B}{\ln c}\left(c^{x}-1\right)\right] \\
& q_{x}=1-\exp \left[-\frac{B c^{x}}{\ln c}(c-1)\right]
\end{aligned}
$$

Didalam asuransi syariah tanpa unsur tabungan, premi yang dibayarkan oleh peserta dikhususkan untuk dana kebajikan (dana tabarru'). Perhitungan dana Tabarru' menggunakan metode Cost of Insurance (COI). Cost of Insurance terdiri dari beberapa komponen yaitu: tabel mortalita yang digunakan, asumsi hasil investasi (i) dan asumsi biaya pengelolaan ( $\alpha$ ) [9].

Perhitungan presentase dana Tabarru' dengan metode Cost of Insurance adalah

$$
\operatorname{COI}_{x}=\frac{v \cdot q_{x}}{1-\alpha}=\frac{\left(\frac{1}{1+i}\right) \cdot q_{x}}{1-\alpha}
$$

Dimana,

$\mathrm{COI}_{x}:$ Cost of Insurance bagi peserta yang berusia $\mathrm{x}$ tahun

$q_{x} \quad$ : Peluang meninggal seseorang yang berusia $x$ tahun

i : asumsi tingkat investasi

$\alpha \quad$ : asumsi biaya pengelolaan

Substitusi persamaan (8) ke persamaan (9) sehingga didapatkan dana tabarru' dengan metode Cost of Insurance berdasarkan Hukum Mortalita Gompertz.

$$
\operatorname{COI}_{x}=\frac{\left(\frac{1}{(1+i)} \cdot\left(1-\exp \left[-\frac{B c^{x}}{\ln c}(c-1)\right]\right)\right)}{1-\alpha}
$$

\section{Hasil dan Diskusi}

Berdasarkan persamaan (8) dapat digunakan untuk mencari para meter B dan c sebagai berikut:

$$
\begin{aligned}
\text { Publikasi }{ }^{q_{x}} & =1-\exp \left[-\frac{B c^{x}}{\ln c}(c-1)\right]_{\mathrm{ka}} \\
1-q_{x} & =\exp \left[-\frac{B c^{x}}{\ln c}(c-1)\right] \\
\ln \left(1-q_{x}\right) & =-\frac{B c^{x}}{\ln c}(c-1) \\
\ln \left(\frac{1}{\left(1-q_{x}\right)}\right)^{-1} & =-\frac{B c^{x}}{\ln c}(c-1) \\
-\ln \left(\frac{1}{\left(1-q_{x}\right)}\right) & =-\frac{B c^{x}}{\ln c}(c-1) \\
\ln \left(\frac{1}{\left(1-q_{x}\right)}\right) & =\frac{B c^{x}}{\ln c}(c-1) \\
\ln \left(\ln \left(\frac{1}{\left(1-q_{x}\right)}\right)\right) & =\ln \left(\frac{B c^{x}}{\ln c}(c-1)\right) \\
\ln \left(\ln \frac{1}{\left(1-q_{x}\right)}\right) & =\ln c^{x}+\ln \left(\frac{B}{\ln c}(c-1)\right)
\end{aligned}
$$




$$
\ln \left(\ln \frac{1}{\left(1-q_{x}\right)}\right)=x \ln c+\ln \left(\frac{B}{\ln c}(c-1)\right)
$$

Dengan bantuan Microsoft Excel didapatkan persamaan regresi untuk laki-laki dan perempuan dari persamaan (11), masing-masing adalah

$$
\hat{y}=0,0947634895614941 x-9,95708293064181
$$

dan

$$
\hat{y}=0,0927343544084347 x-10,3025482984192
$$

Sehingga didapatkan parameter Gompertz B=0,0000451807783621278 dan c=1,09939880508156 untuk laki-laki dan $B=0,0000320160323677938$ dan $c=1,09717023811538$ untuk perempuan. Substitusi $c$ dan B kedalam persamaan (4) untuk melengkapi kolom-kolom tabel mortalita Gompertz.

Hasil untuk tabel mortalita menggunakan hukum Gompertz.

Tabel 1. Tabel Mortalita Laki-laki Menggunakan Hukum Gompertz

\begin{tabular}{ccccc}
\hline $\mathrm{x}$ & $\mathrm{l}_{\mathrm{x}}$ & $\mathrm{d}_{\mathrm{x}}$ & $\mathrm{q}_{\mathrm{x}}$ & $\mathrm{p}_{\mathrm{x}}$ \\
\hline 0 & 100000 & 4,738965 & $4,74 \mathrm{E}-05$ & 0,999953 \\
1 & 99995,26 & 5,209754 & $5,21 \mathrm{E}-05$ & 0,999948 \\
2 & 99990,05 & 5,727284 & $5,73 \mathrm{E}-05$ & 0,999943 \\
$\vdots$ & $\vdots$ & $\vdots$ & $\vdots$ & $\vdots$ \\
110 & 0,010743 & 0,008563 & 0,7971 & 0,2029 \\
111 & 0,00218 & 0,00218 & 1 & 0 \\
\hline
\end{tabular}

Tabel 2. Tabel Mortalita Perempuan Menggunakan Hukum Gompertz

\begin{tabular}{ccccc}
\hline $\mathrm{x}$ & $\mathrm{l}_{\mathrm{x}}$ & $\mathrm{d}_{\mathrm{x}}$ & $\mathrm{q}_{\mathrm{x}}$ & $\mathrm{p}_{\mathrm{x}}$ \\
\hline 0 & 100000 & 3,354693 & $3,35 \mathrm{E}-05$ & 0,999966 \\
1 & 99996,65 & 3,68054 & $3,68 \mathrm{E}-05$ & 0,999963 \\
2 & 99992,96 & 4,038023 & $4,04 \mathrm{E}-05$ & 0,99996 \\
$\vdots$ & $\vdots$ & $\vdots$ & $\vdots$ & $\vdots$ \\
110 & 9,18759 & 5,46427 & 0,594745 & 0,405255 \\
111 & 3,72332 & 3,72332 & 1 & 0 \\
\hline
\end{tabular}

\section{Publikasi IImiah Matematika}

Dalam perhitungan presentase dana tabarru' dengan hukum mortalita Gompertz menggunakan asumsi tingkat investasi $5 \%, 10 \%, 15 \%$ dan biaya pengelolaan yaitu $30 \%$ dan $50 \%$. Dibawah ini merupakan simulasi perhitungan dana tabarru' untuk laki-laki dengan biaya pengelolaan $30 \%$.

Dengan $\mathrm{i}=5 \%$ maka $\mathrm{v}=0,952380952$

$\mathrm{COI}_{0}=\frac{v \cdot q_{0}}{1-\alpha}=\frac{(0,952380952) \cdot(0,0000473896538669942)}{1-0,30}=0,0000644757195469309$

$\mathrm{COI}_{1}=\frac{v \cdot q_{1}}{1-\alpha}=\frac{(0,952380952) \cdot(0,0000521000061245929)}{1-0,30}=0,000070884362074276$

$\mathrm{COI}_{2}=\frac{v \cdot q_{2}}{1-\alpha}=\frac{(0,952380952) \cdot(0,0000572785361620425)}{1-0,30}=0,0000779299811728469$

$\operatorname{COI}_{111}=\frac{v \cdot q_{111}}{1-\alpha}=\frac{(0,952380952) \cdot(1)}{1-0,30}=1,36054421768707$

Dengan $\mathrm{i}=10 \%$ maka $\mathrm{v}=0,909090909$ 
$\mathrm{COI}_{0}=\frac{v \cdot q_{0}}{1-\alpha}=\frac{(0,909090909) \cdot(0,0000473896538669942)}{1-0,30}=0,0000615450050220704$

$\mathrm{COI}_{1}=\frac{v \cdot q_{1}}{1-\alpha}=\frac{(0,909090909) \cdot(0,0000521000061245929)}{1-0,30}=0,0000676623456163544$

$\mathrm{COI}_{2}=\frac{v \cdot q_{2}}{1-\alpha}=\frac{(0,909090909) \cdot(0,0000572785361620425)}{1-0,30}=0,0000743877093013539$

$\vdots$

$\mathrm{COI}_{111}=\frac{v \cdot q_{111}}{1-\alpha}=\frac{(0,909090909) \cdot(1)}{1-0,30}=1,2987012987013$

Dengan $\mathrm{i}=15 \%$ maka $\mathrm{v}=0,869565217$

$\mathrm{COI}_{0}=\frac{v \cdot q_{0}}{1-\alpha}=\frac{(0,869565217) \cdot(0,0000473896538669942)}{1-0,30}=0,0000588691352385021$

$\mathrm{COI}_{1}=\frac{v \cdot q_{1}}{1-\alpha}=\frac{(0,869565217) \cdot(0,0000521000061245929)}{1-0,30}=0,0000647205045025999$

$\mathrm{COI}_{2}=\frac{v \cdot q_{2}}{1-\alpha}=\frac{(0,869565217) \cdot(0,0000572785361620425)}{1-0,30}=0,0000711534610708603$

COI $_{111}=\frac{v \cdot q_{111}}{1-\alpha}=\frac{(0,869565217) \cdot(1)}{1-0,30}=1,24223602484472$

Tabel 3. Tabel Presentase Dana Tabarru' Laki-laki untuk Biaya Pengelolaan Sebesar 30\%

\begin{tabular}{cccc}
\hline & \multicolumn{3}{c}{$\alpha=30 \%$} \\
\cline { 2 - 4 } $\mathrm{x}$ & $\mathrm{i}=5 \%$ & $\mathrm{i}=10 \%$ & $\mathrm{i}=15 \%$ \\
\hline 0 & $6,44757 \mathrm{E}-05$ & $6,1545 \mathrm{E}-05$ & $5,88691 \mathrm{E}-05$ \\
1 & $7,08844 \mathrm{E}-05$ & $6,76623 \mathrm{E}-05$ & $6,47205 \mathrm{E}-05$ \\
2 & $7,793 \mathrm{E}-05$ & $7,43877 \mathrm{E}-05$ & $7,11535 \mathrm{E}-05$ \\
$\vdots$ & $\vdots$ & $\vdots$ & $\vdots$ \\
110 & 1,084490163 & 1,035195155 & 0,99018667 \\
Hublikas136054218 & 1,298701299 & 1,242236025 \\
\hline
\end{tabular}

Tabel 4. Tabel Presentase Dana Tabarru' Laki-laki untuk Biaya Pengelolaan Sebesar 50\%

\begin{tabular}{cccc}
\hline & \multicolumn{3}{c}{$\alpha=50 \%$} \\
\cline { 2 - 4 } $\mathrm{x}$ & $\mathrm{i}=5 \%$ & $\mathrm{i}=10 \%$ & $\mathrm{i}=15 \%$ \\
\hline 0 & $9,0266 \mathrm{E}-05$ & $8,6163 \mathrm{E}-05$ & $8,24168 \mathrm{E}-05$ \\
1 & $9,92381 \mathrm{E}-05$ & $9,47273 \mathrm{E}-05$ & $9,06087 \mathrm{E}-05$ \\
2 & 0,000109102 & 0,000104143 & $9,96148 \mathrm{E}-05$ \\
$\vdots$ & $\vdots$ & $\vdots$ & $\vdots$ \\
110 & 1,518286228 & 1,449273217 & 1,386261338 \\
111 & 1,904761905 & 1,818181818 & 1,739130435 \\
\hline
\end{tabular}

Tabel 5. Tabel Presentase Dana Tabarru' Perempuan untuk Biaya Pengelolaan Sebesar $30 \%$

\begin{tabular}{cccc}
\hline & \multicolumn{3}{c}{$\alpha=30 \%$} \\
\cline { 2 - 4 } $\mathrm{x}$ & $\mathrm{i}=5 \%$ & $\mathrm{i}=10 \%$ & $\mathrm{i}=15 \%$ \\
\hline 0 & $4,5642 \mathrm{E}-05$ & $4,35674 \mathrm{E}-05$ & $4,16732 \mathrm{E}-05$ \\
1 & $5,0077 \mathrm{E}-05$ & $4,78008 \mathrm{E}-05$ & $4,57225 \mathrm{E}-05$ \\
2 & $5,4943 \mathrm{E}-05$ & $5,24456 \mathrm{E}-05$ & $5,01653 \mathrm{E}-05$ \\
\hline
\end{tabular}




\begin{tabular}{cccc}
\hline$\vdots$ & $\vdots$ & $\vdots$ & $\vdots$ \\
110 & 0,80917638 & 0,772395637 & 0,738813218 \\
111 & 1,36054422 & 1,298701299 & 1,242236025 \\
\hline
\end{tabular}

Tabel 6. Tabel Presentase Dana Tabarru' Perempuan untuk Biaya Pengelolaan Sebesar 50\%

\begin{tabular}{cccc}
\hline & \multicolumn{3}{c}{$\alpha=50 \%$} \\
\cline { 2 - 4 } $\mathrm{x}$ & $\mathrm{i}=5 \%$ & $\mathrm{i}=10 \%$ & $\mathrm{i}=15 \%$ \\
\hline 0 & $6,3899 \mathrm{E}-05$ & $6,09944 \mathrm{E}-05$ & $5,83425 \mathrm{E}-05$ \\
1 & $7,0108 \mathrm{E}-05$ & $6,69212 \mathrm{E}-05$ & $6,40115 \mathrm{E}-05$ \\
2 & $7,692 \mathrm{E}-05$ & $7,34238 \mathrm{E}-05$ & $7,02314 \mathrm{E}-05$ \\
$\vdots$ & $\vdots$ & $\vdots$ & $\vdots$ \\
110 & 1,13284693 & 1,081353891 & 1,034338505 \\
111 & 1,9047619 & 1,818181818 & 1,739130435 \\
\hline
\end{tabular}

Dari ilustrasi tabel presentase dana tabarru', dimisalkan akan dihitung dana tabarru' dengan metode Cost of Insurance untuk seorang laki-laki yang berusia peserta asuransi 41 tahun, nilai investasi sebesar $5 \%$ dan biaya pengelolaan sebesar $30 \%$, Peserta asuransi akan mendapatkan uang pertanggungan sebesar Rp.50.000.000,00.

$$
\begin{aligned}
\text { COI }_{41}=\frac{v \cdot q_{41}}{1-\alpha}= & \frac{(0,952380952) \cdot(0,002304)}{1-0,30} \\
& =0,003135244
\end{aligned}
$$

Dana tabarru' $=0,003135244 \times 50.000 .000=156.762 /$ bulan.

\section{Kesimpulan}

Berdasarkan cara pengelolaannya, asuransi syari'ah terbagi kepada dua bagian, asuransi dengan unsur tabungan dan asuransi tanpa unsur tabungan. Untuk menghitung dana tabarru' tanpa unsur tabungan, besarnya dana tabarru' dihitung dengan menggunakan perhitungan Cost of Insurance.

Dengan menggunakan metode kuadrat terkecil didapatkan parameter $\mathrm{B}=0,0000451807783621278$ dan $\mathrm{c}=1,09939880508156$ untuk laki-laki dan $\mathrm{B}=0,0000320160323677938$ dan $\mathrm{c}=1,09717023811538$ untuk perempuan yang digunakan untuk mencari nilai $l_{x}, d_{x}, p_{x}$ dan $q_{x}$ dengan hukum Gompertz.

\section{Publikasillmiah Matematika}

1. Dengan menggunakan beberapa asumsi tingkat investasi dan dan pengelolaan disimpulkan bahwa semakin usia peserta asuransi bertambah, maka semakin tinggi presentase dana tabarru', hal tersebut diakibatkan karena risiko seseorang yang usianya tinggi lebih besar.

2. Berdasarkan tabel presentase dana tabarru' dengan hukum mortalita Gompertz diketahui antara tingkat investasi dengan biaya pengelolaan berbanding terbalik karena semakin rendah tingkat investasi maka presentase semakin tinggi dan sebaliknya untuk biaya pengelolaan.

Hasil perhitungan untuk dana tabarru' dengan studi kasus yang digunakan didapatkan bahwa nilai presentase dana tabarru' sebesar 0,003135244 atau Rp.156.762/bulannya.

\section{Referensi}

[1] Amrin, A. (2006). Asuransi Syariah. Jakarta: PT Elex Media Komputindo.

[2] Abdullah, A. (2011). Meraih Berkah Melalui Asuransi Syariah Ditinjau dari Perbandingan dengan Asuransi Konvensional. Jakarta: Elex Media Komputindo.

[3] Dewan Syariah Nasional Indonesia. (2001). Fatwa DSN NO: 21/DSN-MUI/X/2001 Tentang Pedoman Umum Asuransi Syariah.

[4] Anwar, K. (2007). Asuransi Syariah, Halal \& Maslahat. Solo: Tiga Serangkai. 
[5] Sula, M. S. (2004). Asuransi Syariah (life general): Konsep dan Sistem Operasional . Jakarta: Gema Insani Press.

[6] Ghazali, P. L., Mohd, I., Mamat, M., \& W. Ahmad, W. A. (2012). Integration Model In Premium Life Table Of Family Takaful. Journal of Applied Sciences Research.

[7] Soemitra, A. (2009). Bank dan Lembaga Keungan Syariah. Jakarta: Prenadamedia Group.

[8] Waldi Nopriansyah, Asuransi Syariah, Berkah Terakhir yang tak Terduga, Andi, Yogyakarta, 2016.

[9] Fitria, Amanah. 2016. Analisis Dana Tabarru' Asuransi Jiwa Syariah Menggunakan Perhitungan Cost of Insurance. Buletin Ilmiah Math. dan Terapannya. Volume 05, No. 1 (2016), hal 53-60.

[10] Bismo, Setijo. 2015. Pemodelan Teknik Kimia Lanjut - S2 (Materi Kuliah\#04): Tambahan: Modul Regresi Linier - Dengan Pemrograman dalam MS-EXCEL (Ctrl-Shift + ENTER).

[11] Bowers, N.L., Geerber, H.U, Hickman, J.C., Jenes, D.A., dan Nesbit, C.J., 1997, Actuarial Mathematics, Society of Actuaries, Schaumhurg.

[12] Sholahudin, H. Muhammad. 2011. Kamus Istilah Ekonomi, Keuangan, dan Bisnis Syariah. Jakarta: PT. Gramedia Pustaka Utama.

[13] Fauziah, Fihria. 2017. “Analisis Kesesuaian Hukum Mortalitas Gompertz Terhadap Tabel Mortalitas Indonesia 2011". Skripsi. Univesrtitas Jenderal Soedirman.

[14] Dickson, D. C. M., Hardy, M. R and Waters, H. R. 2013. Actuarial Mathematic for Life Contingent Risks. United States of America: Cambridge University Press.

[15] Futami, Takashi. 1993. Matematika Asuransi Jiwa Bagian I. Oriental Life Insurance Cultural Development Centre, Inc. Tokyo, Japan.

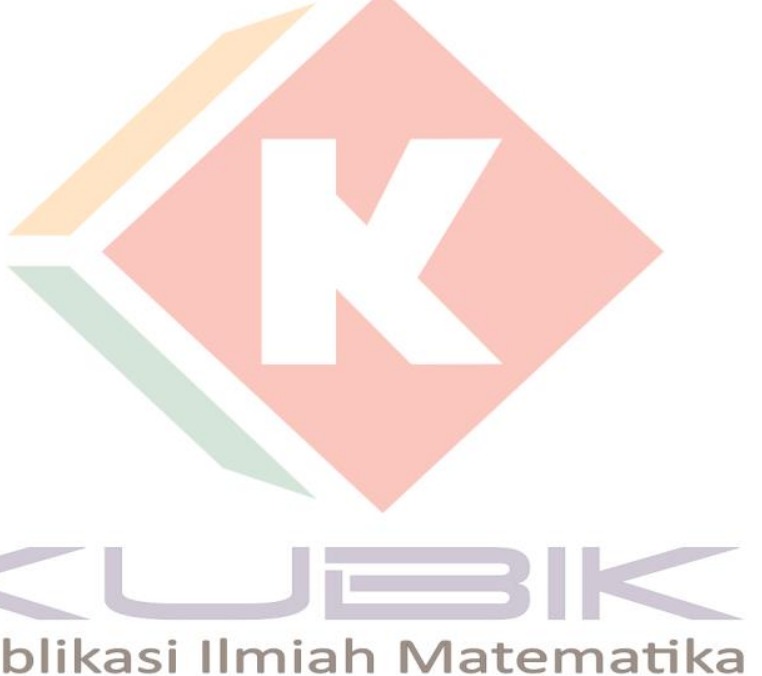

